NBER WORKING PAPER SERIES

\title{
TRADE ADJUSTMENT ASSISTANCE: WELFARE AND INCENTIVE EFFECTS OF PAYMENTS TO DISPLACED WORKERS
}

James A. Brander

Barbara J. Spencer

Working Paper No. 3071

\author{
NATIONAL BUREAU OF ECONOMIC RESEARCH \\ 1050 Massachusetts Avenue \\ Cambridge, MA 02138 \\ August 1989
}

\begin{abstract}
An early version of this paper was prepared for a conference entitled "Designing Policies to Open Trade" held at the University of California, Davis in November 1988. We thank conference organizer Rob Feenstra for suggesting the general topic for the paper, and we thank conference participants for their comments. Financial support from the Centre for International Business Studies at the University of British Columbia is gratefully acknowledged. This paper is part of NBER's research program in International Studies. Any opinions expressed are those of the authors not those of the National Bureau of Economic Research.
\end{abstract}


NBER Working Paper \#3071

August 1989

\title{
TRADE ADJUSTMENT ASSISTANCE: WELFARE AND INCENTIVE EFFECTS
} OF PAYMENTS TO DISPLACED WORKERS

\begin{abstract}
We analyze the welfare effects of conditional trade adjustment assistance (i.e. assistance that is received only if displaced workers remain unemployed), and compare the conditional program with unconditional assistance. Taking the level of assistance as exogenous, we show that either the conditional or unconditional program may impose greater efficiency costs, depending on underlying parameters. We then introduce an explicit social welfare function and solve for the optimal level of assistance for each program. Finally, we compare the optimized values of the two programs. If the distribution of wage offers is uniform, the unconditional program is welfare superior.
\end{abstract}

James A. Brander

Faculty of Commerce and Business Administration University of British Columbia Vancouver, B.C. V6T 1 Y8 Canada
Barbara J. Spencer Faculty of Commerce University of British Columbia Vancouver, B.C. V6T 1 Y8 Canada 


\section{Introduction}

There is a strong body of evidence to support the theoretical presumption that trade liberalization promotes economic prosperity. At the political level, bowever, international trade liberalization is often strongly resisted. Perbaps the most obvious reason for resistance is that while trade liberalization may increase aggregate welfare, it is generally the case that liberalization will make certain clearly identifiable groups worse off. Typically, such groups are workers (and shareholders) associated with an industry that stands to decline as result of liberalization, or whole communities that depend on an industry subject to increasing international competition.

To an economist trained in public finance and welfare economics, such concerns seem perfectly legitimate for, after all, the foundation of welfare economics is the Pareto principle, which suggests that policy changes are desirable if they make some people better of, without leaving others worse off. Since the direct ffects of almost any policy will be to generate both winners and losers, satisfaction of the Pareto principle almost always requires some sort of compensation. As a practical matter, full compensation is rarely likely, and many policies will (and should) go ahead even without compensation, but the idea that some compensation should be fortbcoming to those who are clearly and significantly damaged by changes in trade policy is a very legitimate position.

If we accept the idea that publicly funded compensation is an appropriate policy response to various types of economic events, such as changes in trade policy, we immediately confront the question: what is the appropriate design for compensation or assistance programs? In considering program design one must address two issues. First, what is the efficiency cost af various programs, and secondly, what distributional objective is the program designed to achieve. One can then analyze the nature of any tradeofi between distributional objectives and efficiency. Our objective in this paper is to examine the welfare properties of two competing designs for trade adjustment assistance programs. We focus first on the comparative efficiency costs of the two programs, then introduce a social welfare function incorporating distributional objectives and solve for the 
optimal policy.

The basic efficiency problem with compensation of assistance policies is that they may induce castly incentive effects. This problem has been particularly serious in the area of trade policy, where programs designed to provide temporary assistance to industries or individuals harmed by trade not infrequently seem to bave the effect of creating bong run wards $\alpha$ the state. Specifically, if program benefits are conditional on being in a disadvantaged state, then potential beneficiaries have an incentive to become or remain disadvantaged. This problem is very obvious in the case of trade adjustment assistance for workers: if we pay workers displaced by a trade shock "adjustment assistancen only if they remain unemployed, then we offer them incentives to avoid finding new employment. Several observers bave suggested making trade adjustment assistance unconditional. Consider, for example, the following statement from Lawrence and Litan (1986, p. 104):

"Rather than paying [displaced] workers only as long as they remain unemployed- the method of compensation used in the [U.S. Trade Adjustment Assistance] program since 1981- our proposed system of trade adjustment assistance would encourage readjustment by making additional traderelated compensation available when displaced workers find alternative employment."

Unconditional trade adjustment assistance that pays workers even if they take new jobs avoids the problem of encouraging workers to remain unemployed, but it does require the use of more government revenue to provide a given level of assistance to the target group. If this is viewed as a pure nondistortionary transfer, it has no efficiency consequences, but most economists believe that the marginal cost of government revenue is high. The discussion in, for example, Ballard et. al. (1985) suggests that a marginal cost of between 1.17 and 1.56 per dollar is not unreasonable, i.e., that raising $\$ 1.00$ of government revenue costs the economy between $\$ 1.17$ and $\$ 1.56$, imposing a net efficiency loss of 17 to 56 cents per dollar. Stuart (1984) suggests a somewhat larger but not dissimilar range. (See also Clarete and Whalley (1987) for a comparison of the marginal cost of alternative sources of revenue.)

Even a simple comparison of the costs of conditional and unconditional assistance has some 
interesting subtleties that make it difficult to determine the best policy. In addition, however, the public discussion of assistance programs suggests that it is important for the policy to incorporate distributional or "fairness" objectives. In particular, there is some sense that it is "fair" to partially compensate people who are harmed by some policy decision ar exogenous event. The appropriate method is, however, far from obvious. We introduce a social welfare function that captures this idea and solve for the optimal policy for both conditional and unconditional programs, then compare the optimized values of the two programs.

Trade adjustment assistance programs are only one example of compensatory assistance policies. Most of these policies confront similar tradeoffs between conditional and unconditional approaches. Perhaps the most frequently discussed conditional transfer program is unemployment insurance, where incentive effects are relatively well documented. (For example, Feldstein and Poterba (1984) find that unemployment insurance rases reservation wages, and Blau and Robins (1986) find that higher unemployment insurance bevels reduce various measures of willingness to take co new jobs. It should be noted, however, that Atkinson et. al. (1984) report that the British evidence on incentive effects of unemployment insurance is not very robust.) Our model structure is not specific to the case of trade adjustment assistance, so the results should be taken as general statements about conditional versus unconditional programs. We will continue, however, to use the case of trade adjustment assistance as the motivating example.

In Section 2 we compare the efficiency costs of conditional and unconditional assistance progams, assuming that the level of assistance is exogenously set. In Section 3, using an explicit social welfare function, we derive and compare optimal assistance levels for the two programs. Section 4 gummarizes the main results and discusses other concerns one might have about unconditional assistance programs. 


\section{Efficiency Cost Comparison}

Suppose we have a pool of workers who have been displaced by an exogenous trade shock. We can normalize the size of this pool of workers to be of value 1. Suppose that the old wage was $w^{0}$, and that the value of a worker's time while unemployed is $v$. The workers face heterogeneous employment opportunities, possibly because of pure ramdomness, a possibly because $f$ differences in skills or attributes that were not important in their previous job, but that are important in alternative jobs. These differences could also reflect different transactions costs for different types of workers (those with families as opposed to single workers, etc.) Let the range of alternative wages, $w$, be represented by cumulative distribution function $F(w)$ and associated density function $f(w)$.

We wish to consider a (conditional) assistance program that provides compensation only to workers who remain unemployed, and to compare it with an unconditional program that pays compensation to all displaced workers. Considering such proposals raises the question of what they are supposed to achieve. In order to derive the optimal policy one shousld explicitly identify the benefits of such assistance and maximize the benefit function with respect to the policy variables. We do this in section 3 . In this section, bowever, we simply assume that the assistance level is exogenously set and compare the efficiency costs $\alpha$ the two programs. This cost comparison mates the basic tradeoff as transparent as possible.

Without compensation, a worker will take a new job if the alternative wage he $a$ she can obtain exceeds $v$, the value of his or her time in household activities or leisure. Since the wage is assumed equal to the value of marginal product, this is efficient: workers' time is allocated to its highest value use. However, for those workers with very poor alternatives, this efficiency is of little comfort, for they will be worse off by the amount of the difference between $w^{0}$ and $v$. Consider now a conditional assistance program that pays amount $s$ to displaced workers who do not find new jobs. A displaced worker who remains unemployed gets a net value of $v+s$. If, 
bowever, the worker takes a job, be a whe does not get s, and receives only the wage associated with that $j o b$. The worker therefore compares $v+s$ with alternative wages in deciding whether to take a job. This situtation is illostrated in Figure 1.

\section{Figure 1}

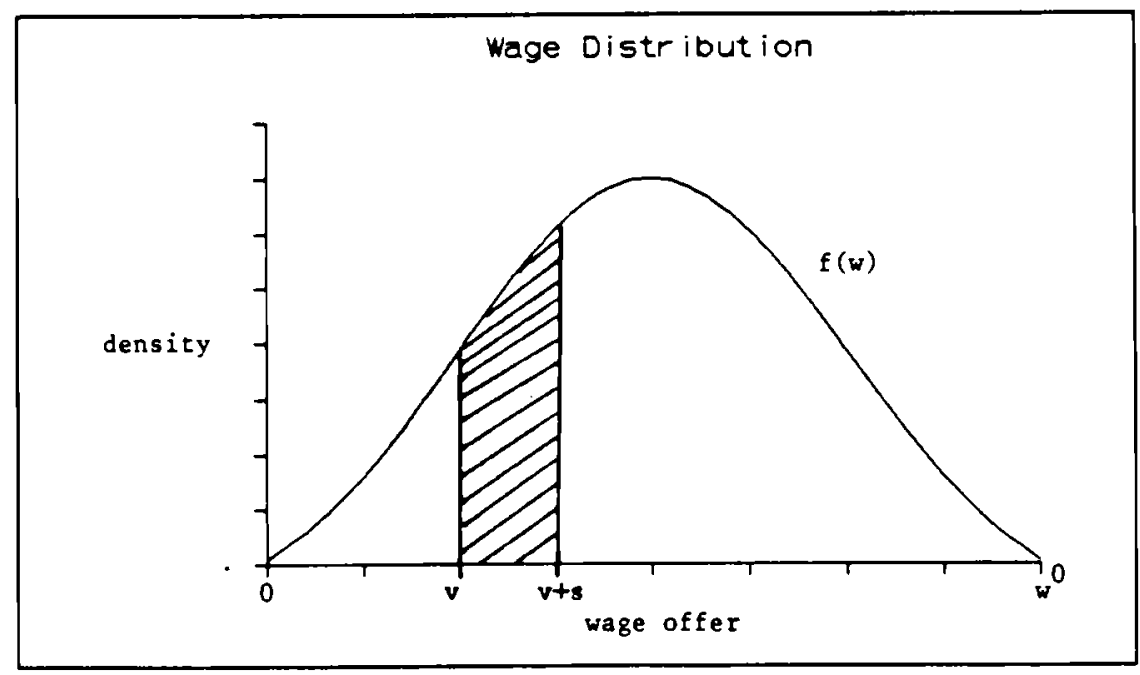

Workers with alternative wages below $v$ do not work, whether or not assistance is offered. Workers with alternative wages between $v$ and $v+s$ do not work if assistance is available, and this is a source of ineficiency: the inefficiency is equal to the difference between the value of work that could be done by such a waker $(w)$, and the value of that time spent not working, as represented by $v$. The fraction of such workers in this category is given by $F(v+g)-F(v)$ and is indicated by the shaded region in Figure 1. The total amount of money transferred to displaced workers is $s F(v+g)$. We assume that there is a (constant) marginal fficiency cost $\delta$ associated with each dollar of revenue raised to fund this transfer. (If the marginal cost of government revenue were 1.30 , then $\delta$ would be .3 . So as to focus strictly on the "efficiency" aspects of the assistance 
programs, we include conly this excess cost of assistance, in effect regarding a simple transfer of resources as neutral. In section 3 we explicitly attribute some social value to transferring resources to displaced workers.)

The total efficiency cost of this compensation program, denoted $C^{c}$, includes both the opportonity cost of lost employment, and the efficiency bos associated with raising revenue to pay for the assistance.

$$
C^{\star}=\int_{v}^{u+s}(w-v) f(w) d w+\delta s F(v+s)
$$

Cost $C^{c}$ is equal to 0 if $s=0$, and is positive for any positive value $o s$, indicating that any positive assistance level will have efficiency costs.

Now consider the unconditional program. To make the basic comparison as transparent as possible, we assume that the level of assistance, $s$, is the same in the unconditional program as in the conditional program. (In section 3 we consider the possibility that the optimal level of compensation might be different in the two programs.) The unconditional program pays com. pensation $s$ to all displaced workers, irrespective of whether or not they obtain new employment. This restores allocational efficiency in worker decisions, for the new choice rule for workers is to take a new job if $w+s>v+s$ : if the economic value of outside employment exceeds the economic value of being wemployed. Furthermore, even those workers who remain unemployed are compensated. The resource cost to the economy of this program, denoted $C^{u}$, is simply the distortionary cost associated with raising the tansfer payment s.

$$
C^{s}=\delta s
$$

If $6=0$, so that the compensation is a pure nondistortionary transfer, then this program has no efficiency cost.

The cost advantage of the unconditional program, denoted $A$, is the difference in cost between the two programs:

$$
A=C^{c}-C^{u}=\int_{v}^{v+s}(w-v) f(w) d w-\delta s(1-F(v+s))
$$


The unconditional program is superior from the effiency point of view if $A$ is positive. To get a sense of whether $A$ is likely to be positive for reasonable parameter values, consider the following example.

\subsection{An Example}

Suppose that the old wage, $w^{D}$ is normalized to equal 1 , and that alternative offers are distributed uniformly over the range $[0,1]$. Assume that $v+s \leq 1$, (i.e. compensation does not "overcompensate" those who remain unemployed). The value $(1-F(v+s))$ in expression (3) is the fraction of displaced workers who would take a job even if assistance $s$ were conditional on being unemployed. This fraction depends on $s, v$, and the distribution of $w$.

For the uniform distribution $f(w)=1$ and the integral in expression $(3)$ is $\int_{v}^{v+1}(w-v) d w=$ $w^{2} / 2-\left.w v\right|_{0} ^{v-\bullet}=s^{2} / 2$. Denoting cost difference $C^{\star}-C^{v}$ by $A$, we have:

$$
A=C^{c}-C^{v}=s^{2} / 2-s \delta(1-(v+s))
$$

The assistance $s$ in this case can be thought of as a fraction of the overall wage range. If the value of leisure, $v$, is 2 and the value of the old job is 1 , then displaced workers who remain unemployed bave lost 8 , and $50 \%$ compensation to those workers would imply that $s=.4$. If we take the value $\delta=-5$ as reasonable, then equation (4) becomes:

$$
A=C^{c}-C^{u}=.08-.08=0 .
$$

For this particulas contrived example, the conditional and unconditional programs have equal eficiency cost. It is clear that by modifying the parameters slightly we can make either program more costly. For example, if $v=.2, s=3$ and $\delta=.5$, the cost of the unconditional program is $25 \%$ bigher than the cost of the conditional program.

\subsection{Comparative Statics}

More generally, it useful to see how the comparative efficiency of the unconditional program is affected by changes in the underlying parameters $\delta$ and $v$. These comparative static effects are 
easily obtained by taking derivatives of equation (3).

$$
\begin{gathered}
d A / d \delta=-s(1-F(v+s))<0 \\
d A / d v=s f(v+s)-\int_{v}^{v+s} f(w) d w+\delta s f(v+s)
\end{gathered}
$$

First of all, as indicated by equation (6), higher levels of $\delta$ make the unconditional compensation program less attractive. Increases in the efficiency cost of raising revenue to finance the program simply make the disadvantage of the unconditional program more severe, as the unconditional program requires more money for a given level of subsidy, s.

As implied by equation (7), the effect of an increase in the value of lesiure, $v$, is ambignous in principle, but it would tend to favour the unconditional program, and would definitely do so if the distribution of alternative wage affers vere uniform. With a uniform distribution, the first two terms of equation (7) exactly offset each other, indicating that changes in $v$ do not affect the amount of inefficient unemployment. This leaves only a positive third term, reflecting the fact that increases in the value of leisure increase the total number of workers receiving the assistance payment. Since each dollar paid has resource cost $\delta$, the rate $\alpha$ increased cost for the conditional program is $\delta s f(v+s)$. The cost of the unconditional program is unchanged by changes in $v, s o$ the net effect of increases in $v$ is to make the conditional program relatively more costly.

For non-uniform distributions of $w$, the amount of inefficient unemployment under the conditional program does, in general, depend on $v$. Using Figure 1, we can see that an increase in $v$ shifts the range of inefficient unemployment to the right. This will raise inefficient unemployment if the density of wage offers is rising over this region, as in Figure 1, which would tend to make the conditional program more costly. On the other hand, if the density function is falling over this segion, inefficient unemployment will fall, tending to reduce the relative cost of the conditional program.

These comparative static effects are summarized in Proposition 1. 


\section{Proposition 1}

i) Increases in the excess cost of raising revenue make the uncoaditional program leas attractive.

ii) Raising the value of kisure tends to make the unconditional program more attractive, and definitely does so if the distribution of alternative wage offers is wiform. *t*

A corollary to part ii) of Proposition 1 is that an improvement in oatside prospects (i.e. an upward shift in the distribution of wage offers), balding the vive of leisure constant, will tend to make the unconditional program less attractive. Part i) of Propocition 1 also allows the following observation. If $v$ nere low relative to $w^{0}$, but most workers had alternative wage offers that were very close to $w^{0}$, and if $s$ were such that $v+s$ were bwer than most alternative wage offers, then the conditional program would be more attractive, for most wakess would take alternative jobs, even though the subsidy is offered anly for those who remain unemployed. In this case, making the subsidy unconditional greatly increases the resource cost of the program, and has very little impact on the employment decision. Conversely, if most workes have alternative offers that are far from $w^{\circ}$, and $s$ is such that $v+s>w$ for most workers, then the moonditional program costs lit tle more than the conditional program, and substantially improves the efficiency of employment decisions.

These results indicate that the relative efficiency of unconditional as opposed to conditional compensation is very sensitive to the underlying economic strocture of the problem. During a recession the unconditional program might be preferred, becanse the distribution of alternative offers is poor, while in a boom the conditional program woold be more efficient.

\section{Optimal Assistance Programs}

Section 2 considers a pure efficiency cost comparison of conditional and unconditional assistance to displaced workers, assuming that the actual assistance brel in exogenous. Our next step is to investigate the optimal level of assistance for both the conditional and unconditional regimes, 
and then to compare the two regimes at their optimal assistance levels. Considering this problem forces to confroat a difficult but important question: what exactly are assistance programs of this sort supposed to achieve? More formally, what is the objective function that should be maximized in selecting an "optimal" policy?

One standard approach to optimal policy selection is to specify a social welfare function in which different individuals may be given different weights, possibly depending on some conditioning variable such $s$ income. It is our view, however, that piecemeal assistance programs are based in part on notions related to the Pareto principle: that there is social value in partially compensating individuals who are disadvantaged by some policy or other shock. The amount of the social value probably depends (inversely) on the relative wealth of the disadvantaged group, but even in cases where the disadvantaged group has higher average income than those funding the transfer (taxpayers) there seems to be some value placed an compensation. Whether such value judgements are reasonable is 2 matter of some controversy in the literature on the philosophical bondations of welfare measure, and we do not propose to resolve that controversy bere. We simply observe that if the motivation for various assistance programs is that partial compensation to the status quo has some social welfare significance, then certain policy results are implied.

One fairly natural way of incorporating a value of compensation is to assume that some positive value is associated with transferring income to displaced workers who are made worse of by a trade shock, up to the utility level at which they are fully compensated. While this is coly coe of several reasonable alternative specifications, we feel that it is useful starting point or benchmark for piecemeal (i.e. program-specific) welfare analysis. (See Deardorff (1986) for a related discussion.)

More formally, worker utility is simply equal to money income plus utility from leisure if unemployed. Social welfare is equal to aggregate private ntility, except that displaced workers with atility levels below $w^{0}$ have weight $1+\alpha$ applied to them, instead of weight 1 . If displaced workers have final utility above $u^{0}$, then that portion of their income below $\boldsymbol{w}^{0}$ receives weight 
$1+a$, and that portion above receives weight 1.

Let $W^{0}$ represent social welfare, let $N$ represent the total size of the worker pool in the rest of the economy (relative to the pool of displaced workers, which is assumed to be of size 1), and let $y$ be the average income in the rest of the economy. In the absence of an assistance program, aggregate social welfare is then given by:

$$
W^{0}=(1+a)\left[v F(v)+\int_{*}^{\infty} w f(w) d w\right]+N y
$$

\subsection{Conditional Assistance}

Now consider the conditional program. In this case displaced workers have utility level $\boldsymbol{w}$ if they take new jobs, and utility level $v+s$ if they remain unemployed. The total assistance payment must be financed at cost $1+\delta$ per dollar raised. Setting out the maximization problem associated with maximizing welfare is simplified if we recognize at the outset that it will never be optimal to provide an assistance level of more than $w^{0}-v$. If the assistance level did exceed $w^{0}-v$, then all workers would have net utility in excess of $w^{0}$. Thus the subsidy would, at the margin, take resources from the rest of the economy at $\cos t 1+\delta$ (or "excess cost" $\delta$ ), but would only have value 1 when transferred to displaced workers to rise their incomes above $w^{D}$. Such a transfer reduces social welfare at rate $\delta$ and therefore cannot be optimal. Total welfare, $W^{c}$, can then be written:

$$
W^{c}=(1+a)\left[(v+s) F(v+s)+\int_{v+\cdot}^{w^{0}} w f(w) d w\right]-(1+\delta) s F(v+s)+N y
$$

We denote net benefit $W^{c}-W^{0}$ by $B^{c}$. Subtracting equation (8) from (9) and rearranging yields the following expression for $B^{c}$.

$$
B^{c}=(\alpha-\delta) s F(v+s)-(1+\alpha) \int_{v}^{v+\bullet}(w-v) f(w) d w
$$

The first term represents the value of transferring total assistance $s F(v+s)$ of social value $1+\alpha$ per dollar at social cost $1+\delta$ per dollar, yielding a net benefit of $\alpha-\delta$ per dollar. The second term 
represents the forgone value of earnings by those displaced workers who have wage offers above $v$ but below $v+s$ and who therefore choose to remain unemployed. Note that these earnings have social value $1+\alpha$ per dollar because, if earned, they would have gone to displaced warkers earning less than $w^{0}$.

Maximizing $B$ yields three possible types of solutions. There may be a corner solution at $s=0$, there may be a corner solution at $s=w^{0}-v$, or there may be an interior solution characterized by $d B^{c} / d s=0$.

$$
d B^{c} / d s=(\alpha-\delta) F(v+s)-(1+\delta) s f(v+s)
$$

Setting expression (11) to zero and solving for s yields the following solution.

$$
s=(\alpha-\delta) F(v+s) /[(1+\delta) f(v+s)]
$$

The second order condition for an internal solution is

$$
d^{2} B^{c} / d s^{2}=(\alpha-2 \delta-1) f(v+s)-s(1+\delta) f^{\prime}(v+s)<0
$$

(For the case of a uniform distribution of $w$ over the interval $[0,1]$, the explicit solution for $s$ is $s=(\alpha-\delta) v /(1+2 \delta-\alpha)$ and the second arder conditions imply that $1+2 \delta-\alpha>0$, i.e. that $\delta>(\alpha-1) / 2$ for an interior solution to be possible.)

Corner solutions arise if $d B^{c} / d s$ is positive at $s=w^{0}-v$ or if $d B^{c} / d s$ is negative at $s=0$. The economic intuition of the various types of solution is as follows. If $\alpha$ is smaller than $\delta$, then the preminm placed on transferring income to diplaced workers is not sufficient to offset the efficiency cost of raising revenue, so the optimum is a corner solution at $s=0$. On the other hand, if $\alpha$ is substantially geater than $\delta$, then the transfer motive overwhelms the efficiency cost of raising revenue, and the optimum is a corner solution at full compensation: $s=w^{0}-v$. For values of $\alpha$ that are larger than $\delta$, but not overwhelmingly larger, there is an internal solution for $s$. 


\subsection{Unconditional Assistance}

We now consider the optimal policy under the unconditional assistance regime. We use the letter $\sigma$ to represent the assistance level in this regme to distinguish it from subsidy $s$ for the conditional regime. In this case displaced workers will bave atility $w+\sigma$ if they take jobs at wage $w$ and wage $v+\sigma$ if they remain nnemployed. Workers will take jobs if the wage $w$ exceeds $v$. Note that some workers will be "overcompensated" in this regime, especially those with alternatives close to the ald wage $w^{0}$. Only that fraction of their income below $w^{0}$ is given welfare weight $1+\alpha$. The rest is given weight 1 . As with the conditional program, writing out the welfare function is simplified if we note that it will never be optimal to provide an assistance level exceeding $w^{0}-v$. Higher assistance levels would imply that all displaced workers were overcompensated, imposing net marginal cost $\delta$ per dollar on the economy. Total welfare for this regime, denoted $W^{u}$ can be written as follows:

$$
W^{v}=(1+\alpha)\left[(v+\sigma) F(v)+\int_{v}^{w^{2}}(w+\sigma) f(w) d w\right]-\alpha \int_{w-\infty}^{w^{0}}\left(w+\sigma-w^{0}\right) f(w) d w-(1+\delta) \sigma+N y
$$

Total welfare in this regime is simply total payments to displaced workers multiplied by weight $1+\alpha$, minus $\alpha$ times payments above $w^{0}$, minus the cost of raising the total assistance payment, $\sigma$, plus the value of earnings elsewhere in the economy. Taking the difference, $B^{u}$, between $W^{u}$ and base welfare $W^{\circ}$ yields the following (after some manipulation).

$$
B^{u}=(\alpha-\delta) \sigma-\alpha \int_{\infty}^{w_{0}^{0}}\left(w+\sigma-w^{0}\right) f(w) d w
$$

The first term in equation (13) is the assistance payment multiplied by the difference between the premium on transfers to displaced workers and the excess cost of raising revenue, and the second term subtracts the social transfer premium for payments that lead to incomes above $w^{0}$.

As with the conditional program, the solution is a corner solution at $\sigma=0$ if $\delta$ is larger than $\alpha$. In other words, no assistance is socially warranted if the social value of transferring assistance to displaced workers is less than the efficiency cost of raising revenue. A corner solution at $\sigma=w^{0}-v$ 
arises if $\alpha$ is oufficiently larger than $\delta$. If the social value of compensating displaced workers is very high compared to the cost of raising revenue, then workers should be fully compensated (and some will be overcompensated). Interior solutions arise for intermediate levels of the difference between $\alpha$ and $\delta$ and are characterized by the following first order condition.

$$
d B^{u} / d \sigma=\alpha F\left(\boldsymbol{w}^{0}-\sigma\right)-\delta=0
$$

Expression (14) defines an inplicit solution for $\sigma$. We can interpret this first order condition as capturing the following tradeoff. Increases in $\sigma$ have the advantage of raising workers' compensation, bot as $\sigma$ rises, the fraction of this increased payment going to workers with total income level below $w^{0}$ falls, reducing the marginal social value of further increases in assistance. This declining marginal benefit must be compared with the (constant) marginal efficiency cost $\delta$ of raising more revenue.

\subsection{Comparing conditional and unconditional assistance}

Our task now is to compare conditional and unconditional assistance assuming that the optimal assistance level would be chosen for either regime. In principle, this comparison is ambiguous in that there are circumstances in which either the conditional regime or the optimized unconditional iegine may provide higher social welfare, depending on the underlying parameters $\alpha, \delta$, and $v$, and on the distribution of wage offers. Overall, however, the unconditional program tends to be welfare superior, as indicated by the following two propositions.

\section{Proposition 2}

If the underlying parameters are such that the solution in both regimes is at the full compensation" cornes: $s=\sigma=w^{\rho}-v$, then the unconditional regime offers higher social welfare than the conditional regime.

\section{Proof}

The difference between the welfare in the two optimized regimes is obtained from equations (10) 
and (13):

$$
B^{v}-B^{c}=(\alpha-\delta)(\sigma-s F(v+s))+(1+\alpha) \int_{0}^{\omega+\bullet}(v-v) f(w) d w-\alpha \int_{\infty}^{\omega_{-\infty}}\left(w+\sigma-w^{0}\right) f(w) d w
$$

Substituting $s=\sigma=w^{0}-v$, and noting that $F(v+s)=F\left(w^{0}\right)=1$, yields:

$$
B^{w}-B^{c}=\int_{v}^{\infty}(w-v) f(w) d w \geq 0
$$

This proves the result. ***

Provided $\alpha$ is sufficiently large relative to $\delta$, the optimal oolutions are corner solutions at $s=\sigma=w^{0}-v$. The efficiency costs of raising revenue to make excess payments under the unconditional regime are then never sufficient to offset the costs of inefficient unemployment in the conditional regime.

It is noteworthy that Proposition 2 holds for any distribution of wages $f(w)$. Other comparative properties do depend on this distribution. Proposition 3 depends on the assumption that $f(w)$ is uniform. The uniform distribution is in some ways a neutral" distribution in that it eliminates effects arising purely from changes in the value of the density function over different ranges of alternative wages.

\section{Proposition 3}

If the distribution of wage offers is uniform and $\alpha>\delta$, then the unconditional program offers strictly higher welfare than the conditional program. If $\alpha \leq \delta$ then the programs are equal and $s=\sigma=0$.

\section{Proof}

See appendix. ***

The basic intuition of why the unconditional program tends to be favoured can be understood as follows. The conditional program has two disadvantages compared to the conditional program, given our welfare function. First, the conditional program creates waste by inducing some workers 
for whom the wage exceeds the value of bisure to remain unemployed $s 0$ as to receive (costly) transfers. Secondly, the conditional program fails to compensate those workers who take jobs but still earn less than the ald wage, $w^{0}$. The marginal social value of a dollar tranferred to these workers is $1+\alpha$, and the unconditional program does channel income to workers in this position. Given that $\alpha>\delta$ this effect tends to make the unconditional program more attractive. The only disadvantage of the unconditional program is that it overcompensates: it pays some workers an overall return above $w^{0}$. This overcompensation conly has value 1 , but it costs $1+\delta$ per unit, so there is a net social loss of $\delta$ for every dollar of overcompensation. For the uniform distribution, however, this cost of overcompensation is always small compared to the first two effects, so the unconditional program dominates.

A high value of $\delta$ relative to $\alpha$ would of course tend to make the unconditional program very unattractive, but it drives both regimes to the corner solution at $s=\sigma=0$. However, as sugggested by the above discussion, there are several circumstances that would improve the relative attractiveness of the conditional program. For example, the conditional program could be preferred if the wage distribution were highly skewed so that very few workers were in the range where they became inefficiently unemployed under a conditional program, but some workers were in a range where they would be overcompensated by the unconditional program.

An extreme version of this situation is as follows. Assume that $\alpha>\delta>0$. Suppose that most altemative wage offers are between 0 and $v$, and the rest are between $w^{*}$ and $w^{0}$ where $w^{*}$ is slightly lese than $w^{0.1}$ For most plausible values of $\alpha$ and $\delta$, the optimal assistance level in the conditional regime will be equal to $w^{*}-v$. This yields no inefficient unemployment (and no overpayment) in the conditional regime. As for the unconditional regime, suitable choices for the various parameters will yield lower maximized welfare than in the conditional regime. The basic problem with the unconditional regime is that its disadvantage (overcompensation at net

\footnotetext{
"This ituation i equivalent to having a minimom mage of $w^{*}$. Worken wo, in the absence of minimum wage legislation, would have recejved ofters between $v$ and $w^{*}$, would cither receive bigher wage offers or no offers at all. The de fato distribution would be with ome mase above $w^{\circ}$ and the reat belor $v$.
} 
social cost $\delta$ per dollar) in wy acute in this case. There is a mbstantial density of workers with alterative wages close to 0 to whom any subsidy payment is mostly overpayment.

\section{Proposition 4}

There are distributions of wage offers and parameter values for which the conditional program is preferred to the unconditional program.

\section{Proof}

A specific example sufficient to establish this result formally is presented in the appendix.

Some plausible modifications to the social welfare function can also increase the relative attractiveness of the conditional program. One modification would be to penalize more heavily the overcompensation that arises onder the unconditional program. As things stands, our welfare function is agnostic about overcompensation, in that payments above $w^{0}$ count on a dollar for dollar basis in social welfare. (It does cost $1+\delta$ per unit so there is some penalty.) Some observers might regard overcompensation in this context as distinctly unfair and might therefore prefer to count overpayments at we value less than 1 per unit. We do not pursue this possibility further, but the effect of this adjustment is firly obvious. A sufficiently large penalty will make the unconditional program leas attractive than the conditional program.

A different modification would be to consider a social welfare function that puts a premium of $\alpha$ only on transfers to those workers whose alternative wage is less than $v$. Transfers to workers with an alteraative wage above o would count only with unit value in social welfare. Such transfers do, bowever, impose an fficiency cost 6 . Since the conditional program compensates fewer such workers, adopting this ociel welfare function enlarges the range of parameter values for which the conditional program is preferred. 


\section{Extensions and Concluding Remarks}

In this paper we have undertaken a systematic comparison of conditional and unconditional trade adjustment assistance using a relatively simple model of worker behaviour. The central tradeof is that a program that makes assistance conditional an remaining unemployed creates an incentive to do precisely that, while a program that compensates all displaced workers on an unconditional basis will end up overcompensating those workers whose alteraatives are nearly as good as their lost jobs. If we recognize that there is a resource cost to raising revenue for such programs, then unconditional programs may well prove unreasonably costly.

We first fix the level of assistance at some exogenous level and show that either program might lead to higher resource cost, depending on underlying parameters. We then raise the more fundamental question: what are compensation programs designed to accomplish? We offer a particular social welfare function that captures the bind of compensation objective that we believe monderlies much of the discussion of assistance programs. We then solve for the optimal level of assistance in both the unconditional and conditional programs and compare the optimized values $\alpha$ the two. The social welfare function we adopt tends to favour the unconditional regime. It is possible, however, for the unconditional program to be favoured for some possible wage distributions. Altering the social welfare function in certain plausible ways also reduces the relative attractiveness of the unconditional regime.

The model we use is fairly simple. Various generalizations can be undertaken without changing the character of the results, including making the value of leisure heterogeneous. We also refer to the policy in question as "trade adjustment assistance", but in fact there is nothing trade-specific in our modelling, so the results are immediately applicable to a wide range of assistance programs.

A matural next step would be to consider partial conditionality; i.e. allowing workers to keep some fraction of their compensation even if they do find jobs. Obviously, the optimal program of this type will always weakly dominate the two extremes and will almost always strictly dominate 
them. Bowever, the information necessary to construct an optimal program is correspondingly more difficult to abtain, and in any case, the optimum would vary with the business cycle (and with other systematic factors as well).

In addition to the tradeoff analyzed in Sections 2 and 3, there are at least three other significant concerns cae might have about unconditional trade adjustment assistance. First, we assumed that there was a given poal of displaced warkers, and that the size of this pool was unaffected by whether trade adjustment assistance was conditional or unconditional. We mould expect, however, that meonditional assistance would increase the pool of displaced workers. After all, if assistance is unconditional, some displaced workers will obtain alternative jobs fffering wages close to their corrent wages, and if they get assistance in addition, they may actually be better off as "displaced" workers than if they kept theis ald jobs. Thus some warkers would have an incentive to become "displaced". Unless the government knows exactly how many workers "should" be displaced by a given trade policy shock, which seem unlikely, frms and workers have an opportunity to exploit taxpayers by distorting the layoff decision. This possibility tends to reduce the relative attractiveness of the unconditional program.

Another concern has to do with rent-seeking. There is a large body of biterature that argues that much of the value of any transfer program will be consumed by resources devoted to bobying and other activities focussed an expanding one's share of the resources being transfered. (See, for example, Bhagwati, Brecher, and Srinivasan (1984).) To the extent that an urconditional trade adjustment assistance program expands the total resources being transferred, increased consumption of resources in rent-seeking is likely to be an additional source of welfare loss.

Finally, there is the general problem of why warkers displaced by a particular class of events (such as trade shocks) should be treated differently than workers displaced for other reasons. For that matter, it is often difficult to distinguish whether a particular group of workers has been displaced by an international trade "event" or by some $\alpha$ her event, $\alpha$ by some combination of shocks emanating from various sources. 
The general point that our results emphasize is that optimal policy desigm is very sensitive (over empirically relevant ranges) to underlying parameter values, particularly the cost of raising revenue. The results also reinforce the obvious point that we need to be clear about the objectives of assistance policies before we can talk usefully about appropriate policy design. 


\section{Appendix}

\section{Proof of Proposition 3}

First, note that if $\alpha \leq \delta$, then no assistance is called for under either the conditional or unconditional regimes, and the two programs are equivalent.

Our main objective is to show that if $\alpha>\delta$ and the distribution of wage offers is uniform, then the unconditional program is always preferred to the conditional program. Without loss of generality we may assume that the old wage is 1 and that wage offers are distributed on [0,1]. Rewriting expression (15) for the uniform distribution yields:

$$
B^{u}-B^{C}=[\sigma(2(\alpha-\delta)-\alpha \sigma)-s(2(\alpha-\delta)(v+s)-(1+\alpha) s)] / 2
$$

There are four potential cases to consider: both s and $\sigma$ could be corner solutions, both could internal solutions, $\alpha$ ane could be at a corner while the other is interior. The case in which botb $s$ and $\sigma$ are at corner solutions has been covered by Proposition 2.

Now consider the case where $s$ is internal. From (11) and (14) $d$ the text we obtain $s=$ $(\alpha-\delta) v /(1+2 \delta-\alpha)$ and, from (A1)

$$
B^{u}-B^{c}=[\sigma(2(\alpha-\delta)-\alpha \sigma)-s(\alpha-\delta) v] / 2
$$

If $\sigma$ is at a corner, we have $\sigma=1-v$ and $\delta<\alpha v$. From (A2),

$B^{u}-B^{c}=[\sigma(\alpha v-\delta)+(\alpha-\delta)(\sigma-s v)] / 2$. Noting that $\sigma>s v$ since $\sigma>s$ and $v<1$, it follows that $B^{u}>B^{c}$.

If $\sigma$ is internal then $\sigma=(\alpha-\delta) / \alpha$, and from (A2)

$$
B^{u}-B^{c}=(\alpha-\delta)^{2}\left(1+2 \delta-\alpha-\alpha v^{2}\right) / \alpha(1+2 \delta-\alpha)
$$

For $\sigma$ to be internal it must be the case $\delta>\alpha v$ which implies that $-\delta v<-\alpha v^{2}$. Substituting this in (A2) then allows us to write:

$$
B^{v}-B^{c}>(\alpha-\delta)^{2}(1+2 \delta-\alpha-\delta v) / \alpha(1+2 \delta-\alpha)
$$


For $s$ to be internal we must bave $1+2 \delta-\alpha>v(1+\delta)>\delta v$. It then follows from (A4) that $B^{u}>B^{c}$.

Finally, consider the case in which $s$ is at corner: $s=1-v$ and $\sigma$ is internal at $\sigma=(\alpha-\delta) / \alpha$. From (A1) we can obtain:

$$
2\left(B^{u}-B^{c}\right)=(\sigma-s)(\alpha v-\delta)+s^{2}>0
$$

Expression (A5) must be positive as $s>\sigma$ and $\alpha v-\delta<0$ if $\sigma$ is internal. ***

\section{Proof of Proposition 4}

An example in which the conditional program dominates the unconditional program

Consider the following parameter values: $\alpha=.5, \delta=.45, v=2, \boldsymbol{w}^{0}=1$, and $w^{*}=8$.

Suppose that the distribution of alternative wage offers is piecewise uniform with the following density:

$$
f(w)= \begin{cases}4 & \text { if } 0 \leq w \leq 2 \\ 0 & \text { if } .2<w<.8 \\ 1 & \text { if } .8 \leq w \leq 1.0\end{cases}
$$

Thus most workers ( $80 \%$ of them) receive alternative offers less than the value $\alpha$ leisure, while the other $20 \%$ receive offers of between $80 \%$ and $100 \%$ of the old wage.

For the conditional regime, we calculate the optimal value of $s$ using first order condition (11) from the text. At $s=w^{*}-v=.6$ the derivative $d B^{c} / d s$ is negative, while at any $s<w^{*}-v$ the derivative is positive, implying that the solution is a corner solution at $s=w^{*}-v=.8-.2=.6$. This is the subsidy level that raises all workers receiving offers below $v$ up to utility level $w^{*}$, but it induces no inefficient unemployment. Any further increases in $s$ would generate inefficient unemployment.

As for the unconditional regime, the optimal value of $\sigma$ is obtained fom first order condition (14), from which it follows that the solution is an interior solution at $\sigma=.1$. (The second order condition for an internal solution is satisfied.) Note that $\alpha w^{*}-\delta<0$ so we are not at a corner solution. 
Noting that $F(v+s)=\&$ and that all integrals over the range $v$ to $v+s$ are zero, we can use expression (15) to calculate the difference between the marimized value of the two regimes. The difference $B^{c}-B^{*}$ is .02 . Recalling that we have sormalized the ald wage to be 1 and the size of the worker pool to be 1 , this means that the conditional regime offers an improvement in social value over the anconditional regime of about $2 \%$ of the dd wage per worker. 


\section{References}

Atkinson, A.B., J. Gomullea and J. Micklewright, (1984), "Unemployment Benefits, Duration, and Incentives in Britain" Journal of Public Economics 23, 3-26.

Ballard, C.L., J.B. Shoven and J. Whalley, (1985), "General Equilibrium Computations of the Marginal Welfare Costs of Taxes in the United States", American Economic Review 75 (March) 128-138.

Bhagwati, J.N., R.A. Brecher, and T.N. Srinivasan (1984), "DUP Activities and Economic Theory", European Economic Review 24, 291-307.

Blan, D.M. and P.K. Robine, (1986), "Job Search, Wage Offers, and Unemployment Insurance" Journal of Public Economics 29, 173-197.

Clarete, RL. and J. Whalley, (1987) "Comparing the Marginal Welfare Costs of Commodity and Trade Taxes" Journal of Public Economics 33, 357-362.

Deardorf, A.V. (1986), "Safeguards Policy and the Conservation Social Welfare Function" University of Michigan Economics Discussion Paper 173.

Feldstein, M. and J. Poterba, (1984) "Unemployment Insurance and Reservation Wages" Jourzal of Public Economics 23, 141-167.

Hufbauer, G. and H. Rosen, (1986) Trade Policy for Troubled Industries (Institute for International Economics, Washington).

Lawrence, R. and R. Litan, (1986), Saving Free Trade: A Pragmatic Approach (Brookings Institution, Washington).

Stuart, C. (1984), Welfare Costs per Dollar of Additional Tax Revenue in the United States, American Economic Review 74, 352-362. 